\title{
MICROCLIMA E PRODUÇÃO DE VIDEIRAS \\ 'NIÁGARA ROSADA' EM CULTIVO ORGÂNICO SOB COBERTURA PLÁSTICA ${ }^{1}$
}

\author{
FLÁVIA COMIRAN ${ }^{2}$, HOMERO BERGAMASCHI ${ }^{3}$, BRUNA MARIA MACHADO HECKLER ${ }^{4}$, \\ HENRIQUE PESSOA DOS SANTOS ${ }^{5}$, DIANE ALBA ${ }^{6}$, EZEQUIEL SARETTA ${ }^{7}$
}

RESUMO - O uso de coberturas plásticas sobre vinhedos tem aumentado no Sul do Brasil, visando a atenuar limitações climáticas. Este estudo objetivou quantificar alterações micrometeorológicas causadas por cobertura plástica e seus efeitos no desenvolvimento e na produção de videiras 'Niágara Rosada', em cultivo orgânico. O estudo foi realizado em Bento Gonçalves-RS, num vinhedo conduzido em sistema latada e submetido a dois ambientes: em céu aberto e coberto por plástico transparente $(160 \mu \mathrm{m})$ em arcos descontínuos. Nos dois ambientes, foram monitoradas radiação fotossinteticamente ativa (RFA) e temperatura do ar. Avaliaram-se fenologia, índice de área foliar (IAF), peso e diâmetro de bagas, teor de sólidos solúveis e acidez total titulável, incidência de doenças fúngicas e rendimento. A cobertura reduziu em um terço a RFA incidente $(-34 \%)$ e aumentou as temperaturas máximas do ar $\left(+3,1^{\circ} \mathrm{C}\right)$. Ela acelerou o ciclo vegetativo das videiras até a maturação, mas retardou a queda de folhas. A cobertura promoveu incrementos de IAF, duração da área foliar e produção de uvas, de 12,3 para 27,1 tha ${ }^{-1}$. Não foi observada incidência de doenças fúngicas no vinhedo coberto. Portanto, a cobertura plástica sobre vinhedos é uma alternativa importante na produção de uvas de mesa no Sul do Brasil, em cultivo orgânico.

Termos para indexação: Vitis labrusca, fenologia, plasticultura.

\section{MICROCLIMATE AND PRODUCTION OF 'NIAGARA ROSADA' GRAPEVINES IN ORGANIC CULTIVATION UNDER PLASTIC COVERING}

\begin{abstract}
The use of plastic covering on vineyards has increased in Southern Brazil, allowing mitigating climate limitations. This study aimed to quantify micrometeorological alterations caused by plastic covering over grapevines 'Niagara Rosada', and the effects on plant growth and grapes production in organic cultivation. A field experiment was conducted in Bento Gonçalves, state of Rio Grande do Sul (Brazil), in a vineyard conducted in pergola system, under two conditions: in open sky and covered with a transparent plastic film $(160 \mu \mathrm{m})$ in discontinuous arcs. The photosynthetically active radiation (PAR) and air temperature were monitored in both environments. The crop phenology, leaf area index (LAI), the weight, diameter, sugar concentration and acidity of grapes, the incidence of fungal diseases, and yield were determined. The plastic covering reduced the incoming PAR in about $34 \%$ and increased the maximum air temperature $\left(+3.1^{\circ} \mathrm{C}\right)$. It accelerated the plant phenology until ripening, but delayed the leaf senescence. LAI and leaf area duration have also increased, while fungal diseases did not occur on covered plants. Grape yields were 12.3 and $27.1 \mathrm{t} \mathrm{ha}^{-1}$ for the uncovered and covered vineyards, respectively. Therefore, the plastic covering may be an important alternative for producing table grapes in organic systems, in Southern Brazil.
\end{abstract}

Index terms: Vitis labrusca, phenology, plasticulture.

\footnotetext{
${ }^{1}$ (Trabalho 191-11). Recebido em: 04-07-2011. Aceito para publicação em: 08-12-2011.

${ }^{2}$ Eng. Agr., M.Sc., Pesquisadora do Instituto Agronômico do Paraná. E-mail: fcomiran@iapar.br

${ }^{3}$ Eng. Agr., Dr., Professor da UFRGS, Pesquisador CNPq. E-mail: homerobe@ufrgs.br

${ }^{4}$ Eng. Agr., M.Sc., Extensionista da Emater-DF. E-mail: bruheckler@hotmail.com

${ }^{5}$ Eng. Agr., Dr., Pesquisador da Embrapa Uva e Vinho. E-mail: henrique@cnpuv.embrapa.br

${ }^{6}$ Eng. Agr., Mestranda em Ciência do Solo, UFRGS. E-mail: dianealba@yahoo.com.br

${ }^{7}$ Acad. Agronomia, Estagiário da Embrapa Uva e Vinho. E-mail: ezequielsaretta@hotmail.com
} 


\section{INTRODUÇÃO}

O Rio Grande do Sul é o Estado brasileiro com a maior produção vitícola, com 53\% da área cultivada no Brasil (IBGE, 2011). Em torno de 90\% da uva produzida destinam-se à agroindústria e somente $10 \%$ são destinados ao consumo in natura. A cultivar Niágara Rosada é uma das principais variedades de uva de mesa cultivada na Serra Gaúcha, a principal região produtora do Estado.

As melhores safras para a viticultura da Serra Gaúcha acontecem em anos com menor precipitação e maior insolação, que possibilitam às uvas melhores condições para maturação (PEDRO JÚNIOR, 2006). Nesse sentido, tem aumentado o uso de coberturas plásticas sobre vinhedos da região, para conter os efeitos do excesso de precipitação, especialmente durante a maturação, para obter frutos de melhor qualidade e alterar o calendário de colheita.

Em resposta às alterações micrometeorológicas nos cultivos protegidos, as videiras modificam seu padrão de desenvolvimento. Na 'Niágara Rosada', em Bento Gonçalves-RS, Schiedeck (1999) verificou diminuição do número de dias entre poda e maturação dentro de estufa plástica, comparando com plantas em céu aberto, em função do maior acúmulo de graus-dia no ambiente protegido.

Também na Serra Gaúcha, Chavarria et al. (2009) verificaram antecipação da brotação de videiras Moscato Giallo, devido ao maior acúmulo de calor sob a cobertura plástica descontínua, além de aumento no período de maturação das uvas, em comparação ao cultivo em céu aberto. No mesmo experimento, Cardoso et al. (2010) observaram maior índice de área foliar nas videiras descobertas, em função do maior número de folhas. Contudo, a área de cada folha e a duração da área foliar foram superiores no vinhedo coberto que em céu aberto.

Em uvas 'Moscato Giallo' cultivadas sob cobertura plástica, Chavarria (2009) verificou tendência de antecipação da maturação. No início da mudança de cor das bagas, o teor de açúcares foi superior e a acidez total foi inferior nas videiras cobertas que em céu aberto.

Estudos sobre cobertura plástica, conduzidos em São Paulo, demonstraram que o excesso de chuvas é um fator limitante ao acúmulo adequado de sólidos solúveis para a produção de vinhos de qualidade (FERREIRA et al., 2004). Entretanto, foram verificadas diferenças significativas na comparação entre ambientes, sendo maiores os teores em céu aberto que no ambiente coberto. Essa diferença pode ser relacionada com a radiação solar, pois, segundo Pedro Júnior et al. (2006), maior insolação nos cachos proporciona maior acúmulo de açúcar.

Outro importante efeito da cobertura plástica é a diminuição ou ausência de doenças nas videiras, em função da redução ou supressão do molhamento do dossel. Esta modificação proporciona redução ou eliminação de tratamentos fitossanitários em ambientes protegidos (CHAVARRIA et al., 2007). Este aspecto pode ser decisivo para viabilizar sistemas de produção orgânica de uvas, devido a restrições no emprego de agrotóxicos para controle de moléstias.

O objetivo deste trabalho foi avaliar alterações micrometeorológicas relacionadas à radiação fotossinteticamente ativa e à temperatura do ar, causadas por cobertura plástica sobre videiras 'Niágara Rosada' cultivadas em sistema orgânico, e seus efeitos sobre o desenvolvimento e a produção das plantas, em particular no índice de área foliar, na maturação, no rendimento de frutos e na incidência de doenças fúngicas, comparando com cultivo em céu aberto.

\section{MATERIAL E MÉTODOS}

O experimento foi realizado num vinhedo de Vitis labrusca, cultivar Niágara Rosada sobre portaenxerto Paulsen 1103, conduzido em sistema latada, durante a safra de 2007/2008. O mesmo foi implantado na sede da Embrapa Uva e Vinho, em Bento Gonçalves-RS (latitude $-29,16^{\circ}$, longitude $-51,53^{\circ}$ e altitude- $640 \mathrm{~m})$. O clima da região é temperado úmido, do tipo fundamental $\mathrm{Cfb}$ (Köeppen). O solo é classificado como Neossolo Litólico (EMBRAPACNPS, 1999). O relevo é ondulado, e a inclinação do terreno é para norte, sendo que as linhas de plantas se encontravam na direção leste-oeste.

'Niágara Rosada' é uma vide de classificação conflitante, ora considerada como variedade/cultivar de . labrusca (AHMEDULLAH; HIMELRICK, 1989; ALVARENGA et al., 1998; 2002), ora como um mutante do híbrido $V$. vinifera $\mathrm{x} V$. labrusca (TAKUSAGAWA, 1952; SOUSA, 1996; TERRA et al., 2003). Considerou-se, neste trabalho, a classificação de 'Niágara Rosada' como cultivar de $V$. labrusca.

Foi adotado o manejo orgânico em todo o vinhedo, desde sua implantação. O controle de plantas daninhas deu-se por meio de roçadas nas entrelinhas das plantas, e a adubação foi feita com composto orgânico à base de borra de suco de uva e engaço. Não foi utilizado nenhum produto para quebra de dormência das gemas e, para controle de doenças, utilizou-se somente calda bordalesa. As pulverizações foram feitas somente no vinhedo descoberto, semanalmente, a partir de 5 de outubro 
de 2007, quando as plantas se encontravam no estádio de alongamento da inflorescência. Nas primeiras aplicações, a concentração da calda bordalesa foi de $0,3 \%$, passando a $0,6 \%$ na floração e $1 \%$ após a floração.

Desde a instalação do experimento, cinco linhas de plantas permaneceram cobertas com filme plástico transparente tipo ráfia, com aditivos antiUV e antigotejo e espessura de $160 \mu \mathrm{m}$. O mesmo foi colocado em forma de arcos descontínuos sobre as fileiras do vinhedo, a $3 \mathrm{~m}$ de altura. Essas linhas constituíram o tratamento 'coberto', sendo que as demais foram mantidas em céu aberto e constituíram o tratamento 'descoberto'.

Foram marcadas 10 plantas nas linhas centrais do tratamento coberto e 10 plantas no vinhedo descoberto, na terceira e quarta linhas, contadas a partir da última linha com cobertura. Nessas videiras, foram avaliados a fenologia, o índice de área foliar e a produção de uvas.

A poda de frutificação foi realizada em 28 de agosto de 2007. Foram deixados, em média, quatro varas e quatro esporões, caracterizando poda mista. No dia 22 de janeiro de 2008, foi realizada a colheita em ambos os tratamentos.

O desenvolvimento das videiras foi acompanhado semanalmente, a partir da poda. Foram analisadas as 20 plantas marcadas (10 em céu aberto e 10 sob cobertura plástica). As determinações dos estádios fenológicos basearam-se na escala fenológica descrita por Eichhorn e Lorenz, citada em Anonymous: EPPO (1984).

$\mathrm{O}$ índice de área foliar (IAF) foi estimado de forma não destrutiva, pelo método descrito por Carbonneau (1976), com algumas adaptações. Semanalmente, em cada área, foi contado o número de folhas das 10 plantas marcadas em cada tratamento e feitas medições de comprimento e largura em 10 folhas por planta. Próximo ao florescimento, foram coletadas amostras de 100 folhas para determinar a área de cada uma, em equipamento eletrônico da marca LICOR, modelo LI 3000, a fim de ajustar o modelo de estimativa de área foliar.

A evolução da maturação foi acompanhada a partir da mudança de cor das bagas. Foram coletadas, semanalmente, 100 bagas no terço médio dos cachos, em ambos os tratamentos. Estas eram pesadas, e o seu diâmetro era medido. A seguir, as uvas eram esmagadas para extrair o mosto, com o qual se determinavam o teor de sólidos solúveis (SS) e a acidez total titulável (ATT). Considerou-se a maturação comercial quando a uva atingiu $15^{\circ} \mathrm{Brix}$, e maturação fisiológica quando atingiu $18^{\circ}$ Brix. A colheita foi realizada em ambos os tratamentos, no dia 22 de janeiro. Entretanto, algumas plantas do tratamento coberto não foram colhidas nesse dia, para que essas avaliações continuassem, e a possibilidade de atrasar a colheita fosse determinada.

Foram colhidos e pesados todos os cachos das 10 plantas marcadas em cada tratamento. Determinaram-se o rendimento por planta $\left(\mathrm{kg} \mathrm{planta}^{-1}\right) \mathrm{e}$ o rendimento médio por área $\left(\mathrm{t} \mathrm{ha}^{-1}\right)$.

Monitorou-se continuamente o microclima em cada tratamento, desde o início da brotação até a queda das folhas. Foram feitas medições contínuas de radiação fotossinteticamente ativa (RFA) acima da cobertura plástica e ao nível dos dosséis e dos cachos, nos vinhedos descoberto e coberto, seguindo procedimentos descritos por Cardoso et al. (2008) e Cardoso et al. (2010). Também foi medida a temperatura do ar junto às plantas e calculado o acúmulo de graus-dia (GD) para cada tratamento, com base nas temperaturas máximas e mínimas diárias, e considerando-se a temperatura base inferior para videira de $10^{\circ} \mathrm{C}$. Utilizaram-se conjuntos de sensores formados por células fotovoltaicas de silício amorfo para medir RFA e pares termoelétricos de cobre-constantan para as temperaturas, os quais foram acoplados a um datalloger Campbel. Foram processadas leituras a cada 30 s e armazenadas médias horárias.

\section{RESULTADOS E DISCUSSÃO}

A presença de cobertura plástica diminuiu em $34 \%$ a radiação fotossinteticamente ativa (RFA) incidente sobre o dossel coberto (Tabela 1). Ao nível dos cachos cobertos, RFA incidente foi, aproximadamente, um terço daquela que incidiu sobre os cachos descobertos. Por outro lado, houve aumento nas temperaturas diurnas junto às videiras cobertas, em comparação com as descobertas. As temperaturas mínima e média diárias foram semelhantes entre os tratamentos, enquanto as máximas diferiram estatisticamente. Estas modificações no microclima, causadas pelo filme plástico junto ao dossel coberto, tiveram efeitos no desenvolvimento e na produção das plantas, em comparação com o vinhedo em céu aberto.

A brotação iniciou antes nas plantas cobertas que nas descobertas, devido ao maior acúmulo de graus-dia sob a cobertura plástica. O pleno florescimento ocorreu em 16 e 18 de outubro de 2007, nos tratamentos coberto e descoberto, respectivamente, sendo de 581 e 536 GD o acúmulo térmico. Em 17 de dezembro de 2007, foram encontradas as primeiras bagas em mudança de cor no vinhedo coberto, embora em número ainda 
insuficiente para caracterizar este estádio fenológico (estádio 35). Em 9 de janeiro de 2008, as videiras de ambos os tratamentos estavam em maturação, mas somente as uvas do tratamento coberto haviam alcançado a maturação de colheita $\left(15^{\circ}\right.$ Brix $)$. Por outro lado, as diferenças entre os tratamentos eram pequenas nesta data, e a colheita foi realizada em 22 de janeiro de 2008, em ambos os tratamentos, quando estavam próximos da maturação fisiológica $\left(18^{\circ}\right.$ Brix $)$.

Segundo Pedro Júnior (2006), a insolação acumulada durante a maturação das uvas influencia diretamente o acúmulo de açúcares. Assim, embora o vinhedo coberto tenha iniciado a maturação antes que o descoberto, devido à maior soma de grausdia, essa antecipação não persistiu até a colheita, em função da menor incidência de radiação solar debaixo do plástico. Resultados semelhantes foram encontrados por Cardoso et al. (2009) e Chavarria et al. (2009). Os autores consideraram que a temperatura do ar foi o fator determinante para o desenvolvimento das plantas, desde o início da brotação até as bagas começarem a mudança de cor, quando a radiação solar se tornou mais importante, prolongando o período de maturação na área coberta.

A partir da maturação de colheita, a cobertura prolongou o desenvolvimento das videiras, retardando a queda de folhas. O início da queda de folhas (estádio 43) deu-se em torno de 45 dias antes no vinhedo descoberto que no coberto, ocorrendo em 30 de dezembro de 2007 e 12 de fevereiro de 2008, respectivamente. Da mesma forma, o final da queda de folhas (estádio 47) deu-se em 4 de abril de 2008 nas plantas descobertas e 24 de abril de 2008 naquelas cobertas.

Assim, as plantas sob cobertura plástica apresentaram maior índice de área foliar (IAF) e maior duração da área foliar que as plantas descobertas (Figura 1). Os valores máximos ajustados de IAF foram 2,1 e 2,5 para videiras descobertas e cobertas, respectivamente, e coincidiram com o estádio de mudança de cor das bagas. Além do maior acúmulo térmico, o qual proporcionou crescimento mais rápido das plantas cobertas, alterações na condição hídrica das plantas podem ter contribuído para aumentar as diferenças observadas em área foliar. Segundo Cardoso et al. (2008), há redução da demanda evaporativa da atmosfera debaixo da cobertura, pela menor disponibilidade de radiação, menor velocidade do vento e maior pressão de vapor d'água no período diurno. As diferenças observadas entre os tratamentos durante o crescimento foliar são semelhantes àquelas verificadas entre folhas de sombra e de sol, referidas por Taiz e Zeiger (2004), já que folhas de sombra têm maior área individual e menos camadas de tecido paliçádico que folhas de sol.

A maior longevidade das folhas no vinhedo coberto também pode ser atribuída à melhor condição fitossanitária das plantas. Pressupõe-se que a fotossíntese se manteve por mais tempo no tratamento coberto, resultando em maior produção de fotoassimilados destinados aos frutos e ao acúmulo de reservas nas plantas. Isto pode proporcionar maiores diferenças entre os tratamentos nas safras subsequentes, com efeito cumulativo e favorável da cobertura ao longo do tempo. Este aspecto é relevante, considerando que o vinhedo era jovem e estava em início de produção comercial, com tendência de aumento no tamanho e vigor das plantas.

O diâmetro e o peso de bagas tiveram diferenças significativas (Tukey a 5\% de probabilidade) entre os tratamentos descoberto e coberto (Figura 2). No vinhedo coberto, o diâmetro foi $5 \%$ maior, e o peso de bagas 20\% maior que em céu aberto. Essas diferenças são coerentes com a menor demanda evaporativa atmosférica sob cobertura plástica, que tende a proporcionar maior turgidez das bagas (RANA et al., 2004; CARDOSO et al., 2008) e contribui para a diferença de rendimento entre os tratamentos. Destaca-se que o diâmetro e o peso das bagas se mantiveram constantes no vinhedo coberto, mesmo quando a colheita foi atrasada por quase 40 dias em relação ao cultivo em céu aberto. Portanto, não haveria diferenças de rendimento, com relação a estes atributos físicos, no caso de haver atraso na colheita.

Quanto à composição química dos frutos, em 9 de janeiro de 2008, houve diferença significativa entre os tratamentos para as duas variáveis (Tukey a 5\% de probabilidade), evidenciando antecipação da maturação no vinhedo coberto (Figura 3). Porém, na avaliação seguinte (16 de janeiro de 2008), as diferenças no acúmulo de açúcares e na quantidade de acidez não se mantiveram. Por ocasião da colheita (22 de janeiro de 2008), o teor de sólidos solúveis (SS) foi superior a $17^{\circ}$ Brix, e a acidez total titulável (ATT) foi próxima de $80 \mathrm{meq} \mathrm{L}^{-1}$ em ambos os tratamentos. Após essa data, no vinhedo coberto, o teor de SS continuou aumentando, atingindo $22^{\circ}$ Brix, enquanto ATT continuou diminuindo e chegou a $53 \mathrm{meq} \mathrm{L}^{-1}$ na última colheita, realizada em 27 de fevereiro de 2008. Estes resultados demonstram que é possível retardar a colheita das uvas de vinhedos 'Niágara Rosada' cobertos com filme plástico, em cerca de 40 dias depois de atingida a maturação de colheita, sem prejuízos à qualidade dos frutos para comercialização. Entretanto, o mesmo não poderia ser recomendado para vinhedos descobertos, sobretudo em função de podridões, que já eram observadas na maturação 
de colheita. A possibilidade de atrasar a colheita poderia proporcionar ganhos financeiros adicionais aos produtores de uvas de mesa, principalmente devido à racionalização no emprego da mão de obra e à possibilidade de comercialização do produto fora do período de maior oferta, assim obtendo melhores preços.

Não houve incidência de míldio e antracnose nas videiras sob cobertura plástica. Por outro lado, no início de dezembro, quando os cachos estavam compactados em ambos os tratamentos, verificou-se a incidência de míldio e antracnose nas plantas descobertas, apesar de terem sido feitas pulverizações semanais com calda bordalesa. Neste vinhedo, em torno de $2 \%$ das folhas e $7 \%$ dos cachos apresentavam sintomas de míldio. A antracnose manifestou-se em $5 \%$ das folhas, $3 \%$ dos ramos e $29 \%$ dos cachos do vinhedo descoberto. Estudos anteriores ressaltaram a necessidade de manejos fitossanitários específicos em ambiente protegido (CHAVARRIA et al., 2007), devido à redução na incidência de doenças, em comparação ao cultivo em céu aberto. Esta mudança de cenário se explica pela estreita interação entre a incidência de patógenos e as condições meteorológicas, em particular a umidade presente no ambiente.
A produção de uvas por planta foi de 4,6 e $10,2 \mathrm{~kg}$, enquanto a produção estimada por área foi de 12,3 e $27,1 \mathrm{tha}^{-1}$ para os tratamentos descoberto e coberto, respectivamente. Portanto, o rendimento do vinhedo em céu aberto representou $45 \%$ do rendimento no tratamento coberto, havendo diferença significativa a $1 \%$ de probabilidade de erro, pela análise de variância. A diferença de rendimento entre os tratamentos pode ser atribuída, mesmo indiretamente, às alterações micrometeorológicas proporcionadas pela cobertura plástica. Segundo Mandelli (2008), a sequência de dias chuvosos, que ocorreu no final de outubro, logo após o pleno florescimento da Niágara Rosada, e no início de novembro de 2007, prejudicou a floração e o "pegamento" de frutos de algumas cultivares. As videiras cobertas, porém, não estiveram sujeitas a esses efeitos. Além disso, a redução na radiação solar incidente no vinhedo coberto tende a proporcionar maior turgidez e expansão celular, devido à redução da demanda evaporativa atmosférica. Também foram alteradas as condições que predispõem a incidência de doenças pelo "efeito guarda-chuva" da cobertura, que tende a evitar o molhamento dos tecidos vegetais.

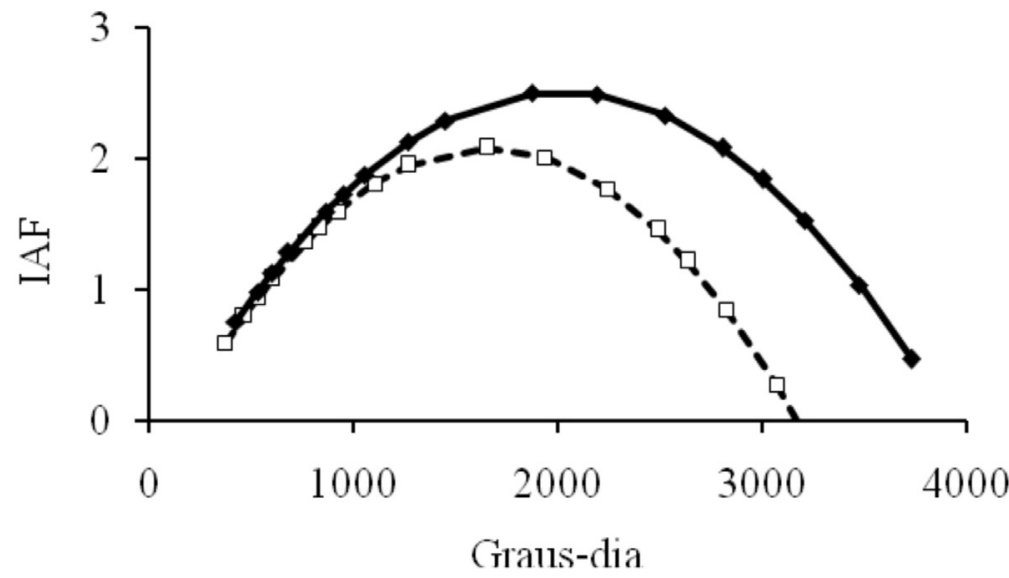

$$
\begin{gathered}
\square \text { IAFdescoberto }=-0,4017+0,0030 * \mathrm{GD}-9,0564-007 * \mathrm{GD}^{2} \\
\mathrm{R}^{2}=0,79 \\
\qquad \mathrm{IAF} \text { coberto }=-0,3079+0,0028 * \mathrm{GD}-6,9468^{-007} * \mathrm{GD}^{2} \\
\mathrm{R}^{2}=0,85
\end{gathered}
$$

FIGURA 1 -Índice de área foliar (IAF) observado ( $\square \bullet$ ) e estimado (--- e - em função de graus-dia acumulados em vinhedo de Vitis labrusca, cultivar 'Niágara Rosada', descoberto e coberto com filme plástico. Bento Gonçalves-RS, 2007/2008. 


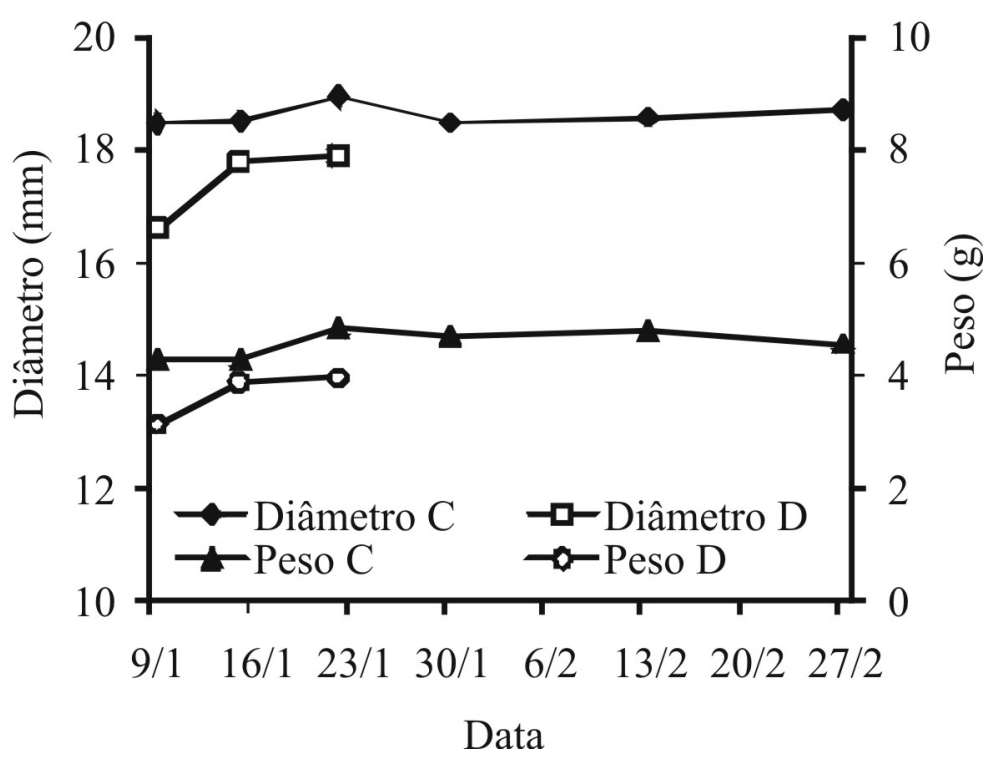

FIGURA 2 - Diâmetro e peso de bagas de videiras Vitis labrusca, cultivar 'Niágara Rosada', descobertas (D) e cobertas com filme plástico (C). Bento Gonçalves-RS, 2008 (diferença significativa ao nível de 5\% de significância, pela análise de variância).

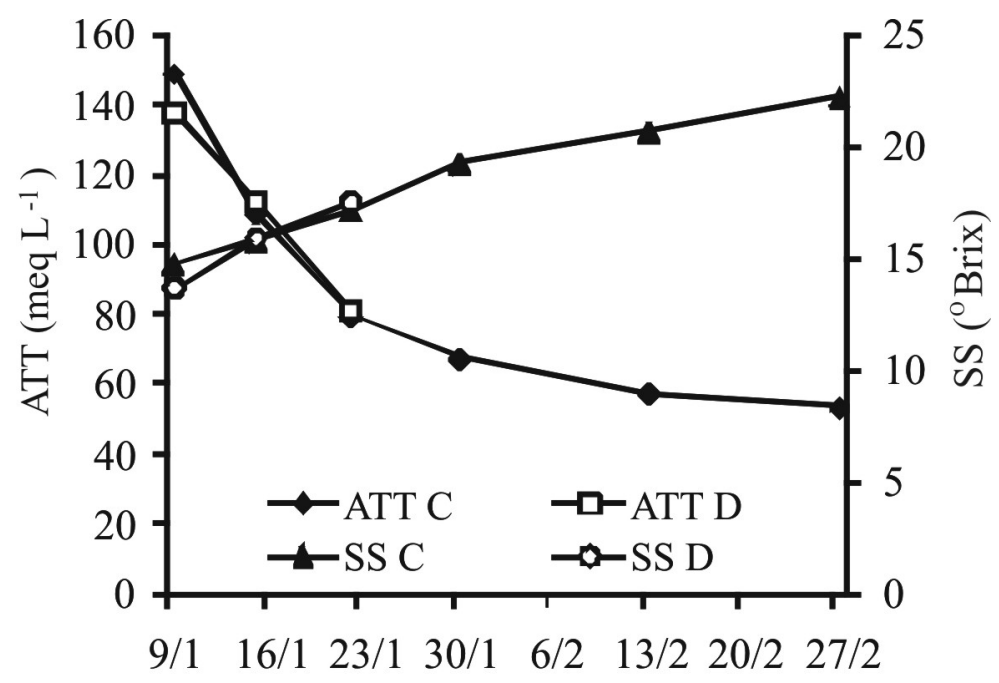

Data

FIGURA 3 - Acidez total titulável (meq $\left.\mathrm{L}^{-1}\right)$ e teor de sólidos solúveis $\left({ }^{\circ}\right.$ Brix) em mosto de videiras Vitis labrusca, cultivar 'Niágara Rosada', descobertas (D) e cobertas com filme plástico (C). Bento Gonçalves-RS, 2008 (diferença significativa ao nível de 5\% de significância, pela análise de variância). 
TABELA 1- Porcentagem de radiação fotossinteticamente ativa, incidente sobre o dossel e ao nível dos cachos, e temperatura do ar junto ao dossel, em vinhedos descoberto e coberto com filme plástico, na média do período vegetativo. Bento Gonçalves-RS, 2007/2008.

\begin{tabular}{lcc}
\hline & Descoberto & Coberto \\
\hline RFA dossel $(\%)$ & 100 & $66^{*}$ \\
RFA cachos $(\%)$ & 31 & $8^{*}$ \\
Temp. mínima $\left({ }^{\circ} \mathrm{C}\right)$ & 15,5 & 15,4 \\
Temp. média $\left({ }^{\circ} \mathrm{C}\right)$ & 20,3 & 21,2 \\
Temp. máxima $\left({ }^{\circ} \mathrm{C}\right)$ & 27,8 & $31,6^{*}$ \\
\hline
\end{tabular}

(* diferença significativa a $1 \%$ de probabilidade, entre tratamentos)

\section{CONCLUSÕES}

1- O uso de cobertura plástica altera o microclima de vinhedos, reduzindo a radiação fotossinteticamente ativa incidente sobre as plantas e aumentando a temperatura do ar no período diurno.

2-O desenvolvimento de videiras 'Niágara Rosada' sob cobertura plástica é acelerado até a maturação e retardado após, em comparação a videiras em céu aberto.

3-O período de colheita das uvas é prolongado, e a queda de folhas é retardada pelo uso da cobertura plástica sobre o vinhedo.

4-. Há aumento no diâmetro e peso de bagas, como também no rendimento de frutos em vinhedo sob cobertura plástica, em comparação com o cultivo em céu aberto.

5- O uso de cobertura plástica sobre vinhedos é uma importante alternativa de manejo em sistemas de cultivo orgânico de uvas de mesa 'Niágara Rosada', em condições de clima úmido.

\section{AGRADECIMENTOS}

Ao CNPq, pela concessão de bolsas e auxílio financeiro. À Embrapa Uva e Vinho, pelo apoio técnico e científico. À UFRGS, pelo suporte institucional e de pessoal. Aos pesquisadores Drs. George Wellington Bastos de Melo e Olavo Sonego, pela participação nos trabalhos de campo.

\section{REFERÊNCIAS}

AHMEDULLAH, M.; HIMELRICK, D.G. Grape Manegement. In : GALLETTA, G.J.; HIMELRICK, D.G. (eds). Small fruit crop management. New Jersey: Prentice Hall, 1989. p.383-408.

ALVARENGA, A.A. et al. Origem e classificação botânica da videira. Informe Agropecuário, Brasília, v.194, p.5-8. 1998.

CARBONNEAU, A. Príncipes et méthodes de mesure de la surface foliaire. Essai de caractérisations des types de feuilles dans genre Vitis. Annales de Amélioration des Plantes, Paris, n.26, v.2, p.327343, 1976.

CARDOSO, L.S.; BERGAMASCHI, H.; COMIRAN, F.; CHAVARRIA, G.; MARODIN, G.A.B.; DALMAGO, G.A.; SANTOS, H.P. dos; MANDELLI, F. Alterações micrometeorológicas em vinhedos pelo uso de coberturas de plástico. Pesquisa Agropecuária Brasileira, Brasília, v.43, n.4, p.441-447, 2008.

CARDOSO, L.S.; BERGAMASCHI, H.; COMIRAN, F.; CHAVARRIA, G.; MARODIN, G.A.B.; DALMAGO, G.A.; SANTOS, H.P. dos; MANDELLI, F. Padrões de interceptação de radiação solar em vinhedos com e sem cobertura plástica. Revista Brasileira de Fruticultura, Jaboticabal, v.32, p.161-171, 2010.

CHAVARRIA, G.; SANTOS, H.P. dos; SÔNEGO, O.R.; MARODIN, G.A.B.; BERGAMASCHI, H.; CARDOSO, L.S. Incidência de doenças e necessidade de controle em cultivo protegido de videira.

Revista Brasileira de Fruticultura, Jaboticabal, v.29, n.3, p.477-482, 2007. 
CHAVARRIA, G.; SANTOS, H.P. dos; MANDELLI, F.; MARODIN, G.A.B.; BERGAMASCHI, H.; CARDOSO, L.S. Caracterização fenológica e requerimento térmico da cultivar Moscato Giallo sob cobertura plástica. Revista Brasileira de Fruticultura, Jaboticabal, v.31, n.1, p. 119-126, 2009.

EMBRAPA-CNPS. Sistema brasileiro de classificação de solos. Rio de Janeiro, 1999. 412 p.

EPPO crop growth stage keys : echelles OEPP des stades de développement des plantes cultivées: Grapevine/Vigne. EPPO Bulletin, Paris, v.14, n2, p. 295-298, 1984.

FERREIRA, M.A.; PEDRO JÚNIOR, M.J.; SANTOS, A.O.; HERNANDES, J.L. Modificação parcial do ambiente de cultivo da videira 'Cabernet Sauvignon' sobre diferentes porta-enxertos: efeito sobre a produção e o teor de sólidos solúveis. Bragantia, Campinas, v.63, n.3, p.439-445, 2004.

IBGE - Instituto Brasileiro de Geografia e Estatística. Levantamento sistemático da produção agrícola/ abril 2011. Disponível em: <http://www.ibge.gov. br/home/estatistica/indicadores/agropecuaria/lspa/ default.shtm $>$ Acesso em: 10 jun. 2011.

MANDELLI, F. Comportamento meteorológico e sua influência na vindima de 2008 na Serra Gaúcha. Bento Gonçalves: Empresa Brasileira de Pesquisa Agropecuária, 2008. (Comunicado Técnico, 8)5. Disponível em: <http://www.cnpuv.embrapa. br/publica/comunicado/cot085.pdf $>$ Acesso em: 06 jan. 2009.
PEDRO JUNIOR, M.J.; PEZZOPANE, J.R.M.; HERNANDES, J.L.; ABRAMIDES, P.L.G. Sistemas de condução da videira 'Niágara Rosada': efeitos na transmissão da radiação solar e na produtividade. Revista Brasileira de Agrometeorologia, Santa Maria, v.14, n.1, p.1-9, 2006.

RANA, G.; KATERJI, N.; INTRONA, M.; HAMMAMI, A. Microclimate and plant water relationship of the "overhead" table grape vineyard managed with three different covering techniques. Scientia Horticulturae, Amsterdam, n.102, p.105-120, 2004.

SCHIEDECK, G. Maturação da uva Niágara Rosada cultivada em estufa de plástico e a céu aberto. Ciência Rural, Santa Maria, v.29, n.4, p.629-633, 1999.

TAIZ, L.; ZEIGER, E. Fisiologia vegetal. 3.ed. Porto Alegre: Artmed, 2004. 719p.

SOUSA, J.S.I. Uvas para o Brasil. Piracicaba: FEALQ, 1996. 791p.

TAKUSAGAWA, H. Chromosome numbers in Vitaceae. Japanese Journal of Genetics, Tokyo, v.27, n.1, p.22-24, 1952.

TERRA, M.M.; PIRES, E.J.P.; POMMER, C.V.; BOTELHO, R.V. Produtividade da cultivar de mesa Niágara Rosada sobre diferentes porta-enxertos, em Monte Alegre do Sul-SP. Revista Brasileira de Fruticultura, Jaboticabal, v.25, n.3, p.549-551, 2003. 